10 Kanffman SL, Stout AP. Hemangiopericytoma in children. Cancer 1960; 13: 695-710.

11 Tulenko JF. Congenital hemangiopericytoma: case report. Plast Reconstr Surg 1968; 41: 276-7.

12 Kent KH. Hemangiopericytoma. AfR 1957; 77: 347-56.

13 Mujahed Z, Vasilas A, Evans JA. Hemangiopericytoma: report of four cases with a review of the literature. $A \mathcal{F} R$ 1959; 82: $658-66$

14 Sutton D, Pratt AE. Angiography of hemangiopericytoma Clin Radiol 1967; 18: 324-9.

15 Yaghmai I. Angiographic manifestations of soft tissue and osseous hemangiopericytomas. Radiology 1978; 126: 653-9.

16 Stephens DH, Sheedy PF, II, Hattery RR, Williamson B, Jr Diagnosis and evaluation of retroperitoneal tumor by computed tomography. AfR 1977; 129: 395-402.

17 Pinson CW, Remine SG, Fletcher WS, Braasch JW. Long term results with primary retroperitoneal tumors. Arch Surg 1989; 124: 1168-73.

18 Lorigan JG, David CL, Evans HL, Wallace S. The clinical and radiologic manifestation of hemangiopericytoma. $A \mathscr{F} R$ 1989; 153: 345-9.

19 Alpern MB, Thorsen MK, Kellman GM, Pojunas K, Lawson TL. CT appearance of hemangiopericytoma. $\mathfrak{J}$ Comput Assist Tomogr 1986; 10: 264-7.

20 Imachi $\mathrm{M}$, Tsukamoto $\mathrm{N}$, Tsukimori $\mathrm{K}$, et al. Malignan hemangiopericytoma of the omentum presenting as an ovarian tumor. Gynecol Oncol 1990; 39: 208-13.
21 Jimenez-Avala M, Diez-Nau MD, Larrad A, et al. Hemangiopericytoma in a male breast. Report of a case with cytologic, histologic and immunochemical studies. Acta Cytologic, histologic and 35: 234-8.

22 Smullens SN, Scatti DJ, Osterholm JL. Preoperative Smullens SN, Scatti DJ, Osterholm JL. Preoperative aid in their removal. Cancer 1982; 50: 1870-5.

23 Smith RB, Machleder HI, Rand RW, Bentson J, Tarbas P. Preoperative vascular embolization as an adjunct to successful resection of large retroperitoneal hemangiopericytoma. $\mathcal{F}$ Urol 1976; 115: 206-8.

24 Staples JJ, Robinson RA, Wen BC, Hussey DH. Hemangiopericytoma - the role of radiotherapy. Int $\mathcal{f}$ Radiat Oncol Biol Phys 1990; 19: 445-51.

25 Craven JP, Quigley TM, Bolen JW, Raker EJ. Current management and clinical outcome of hemangiopericytomas. Am f Surg 1992; 163: 490-3.

26 Munoz AK, Berek JS, Fu YS, Heintz PA. Pelvic hemangiopericytomas: a report of five cases and literature revew. Gynecol Oncol 1990; 36: 380-2.

27 Wong PP, Yagoda A. Chemotherapy of malignant hemangiopericytoma. Cancer 1978; 41: 1256-60.

\title{
Carcinoid syndrome due to a malignant somatostatinoma
}

Ömer Özbakir, Fahrettin Keleștimur, Figen Öztürk, Erdoğan Sözüer, Ali Ünal, Tahir E Patiroğlu, Kadri Güven

\begin{abstract}
Summary
Somatostatinoma is one of the rarest tumours of the endocrine pancreas. Cardinal manifestations of a somatostatinoma include gallstones, mild diabetes mellitus, steatorrhoea, diarrhoea and dyspepsia. Like any other pancreatic islet cell carcinoma, a somatostatinoma may also produce several different hormones such as adrenocorticotropic hormone, calcitonin, vasoactive intestinal polypeptide, pancreatic polypeptide, gastrin, insulin, and glucagon. In many cases, the clinical picture is dominated by the effect of these other hormones. We present a patient with somatostatinoma in which an immunocytochemical study of the specimens from pancreas and liver showed a weak positive reaction for gastrin besides a strong positive reaction for somatostatin. Interestingly, this patient also showed the signs of carcinoid syndrome which was successfully treated with octreotide.
\end{abstract}

Keywords: somatostatinoma, carcinoid syndrome, octreotide

Gut endocrine tumours have a low incidence of about 1 in 200000 population and $60 \%$ of these are carcinoids. ${ }^{1}$ Somatostatinomas appear to be one of the rarest gut endocrine tumours, and the yearly incidence is estimated to be as low as 1 in 40 million people. ${ }^{2}$ In the majority of the patients, metastatic spread is evident at the time of presentation or shortly thereafter.
Metastatic spread is usually to the liver, with involvement of lymph nodes and contiguous spread also being common. It has been suggested that the expression of the classic triad of symptoms may be more common when liver metastases are present. ${ }^{3}$ Total tumour resection is the first line of therapy in patients with pancreatic somatostatinoma, while chemotherapy is also frequently used either as the primary mode of therapy in disseminated disease or as adjunctive therapy after surgery. ${ }^{1}$

Carcinoid syndrome is a clinical entity which is usually caused by the humoral secretions of carcinoid tumours that originate in the midgut. Lesions other than carcinoid tumours sometimes secrete serotonin and present with symptoms of the carcinoid syndrome (see box 1). In its most complete form, the carcinoid syndrome involves several different organ systems such as the vasomotor, cardiopulmonary and gastrointestinal systems. The cardinal manifestations of this syndrome consist of hepatomegaly, cutaneous flushing, facial telangiectasia, hypotension, diarrhoea, endocardial

\begin{tabular}{|l|}
\hline Carcinoid syndrome: causes \\
\hline - carcinoid tumours \\
- medullary carcinomas of the thyroid \\
- oat-cell carcinomas of the lung \\
- nancreatic islet cell cancers \\
- other chromaffin tumours \\
\hline
\end{tabular}

Box 1 
lesions, bronchoconstriction and oedema. Since the liver metabolises most of the serotonin to which it is exposed, the carcinoid syndrome does not often occur from a gastrointestinal primary lesion until massive liver replacement by the tumour has occurred. ${ }^{4}$

We have been unable to find a report in the literature of a patient with pancreatic somatostatinoma leading to a well-documented carcinoid syndrome, although some patients with flushing have been reported ${ }^{5,6}$ and somatostatinoma is known to secrete a variety of hormones and peptides which may affect the clinical presentation.

\section{Case report}

A 50-year-old woman was first admitted to the department of surgery in December 1993 because of severe upper gastrointestinal bleeding with the signs of hypovolaemic shock. In her past medical history, there was nothing but an appendectomy, 21 years earlier. A significant site of bleeding could not be detected though an upper gastrointestinal endoscopy was performed. An abdominal ultrasonogram showed multiple metastatic nodules in the liver with splenomegaly. Her gastrointestinal bleeding could not be controlled by medical measures, and she underwent surgery. During the surgical procedure, a tumoural enlargement at the tail of the pancreas and multiple metastatic nodules in the liver were observed, along with splenomegaly.

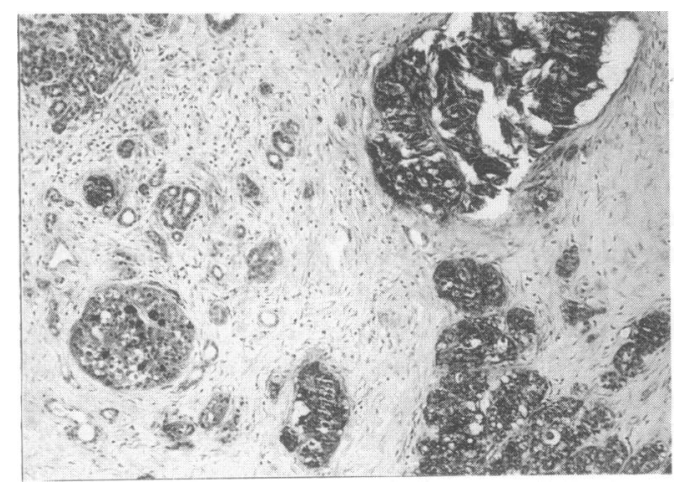

Figure 1 Pancreatic islets and tumour cells giving a positive reaction for somatostatin (immunoperoxidase, $\times 100)$

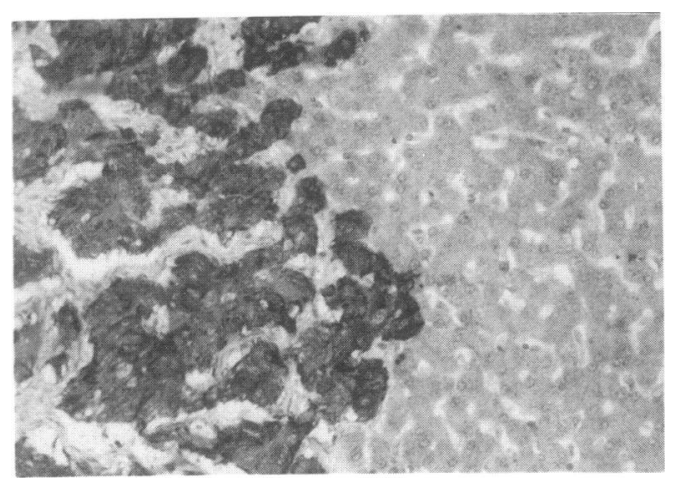

Figure 2 Metastatic tumour cells in the liver giving a positive reaction for somatostatin (immunoperoxidase, $\times 200)$
A total gastrectomy + splenectomy + distal pancreatectomy + roux-en-Y oesophagojejunostomy procedure was performed. A liver biopsy from one of the nodules was also obtained. Histopathological examination revealed a malignant islet cell carcinoma of pancreas with liver metastases. An immunocytochemical study of specimens from both the pancreas and liver was performed which showed a strong positive reaction for somatostatin (figures 1 and 2), a weak positive reaction for gastrin (figures 3 and 4 ) and negative reactions for insulin, glucagon, adrenocorticotropic hormone and pancreatic polypeptide. Two weeks after surgery plasma and serum levels of the following hormones were within the normal range: gastrin $64 \mathrm{ng} / \mathrm{l}$, cortisol $358 \mathrm{nmol} / 1$, insulin $21 \mathrm{pmol} / \mathrm{l}$, Cpeptide $0.93 \mathrm{nmol} / \mathrm{l}$, growth hormone $0.61 \mu \mathrm{g} / 1$ and prolactin $21.44 \mu \mathrm{g} / \mathrm{l}$. Though the level of gastrin was within normal limits, this finding supported the existence of a gastrin-secreting tumour as the entire stomach had been removed. She was put on a once a week 5-fluorouracil regimen and discharged.

The patient was re-admitted to the Department of Internal Medicine in September 1994 with recurrent watery diarrhoea, cutaneous flushing of the head and neck, nausea, and vomiting. Physical examination revealed a cutaneous flushing of the head and neck and increased bowel movements. The serum biochemical values were: fasting blood sugar $7.33 \mathrm{mmol} / 1$, sodium $136 \mathrm{mmol} / 1$, potassium

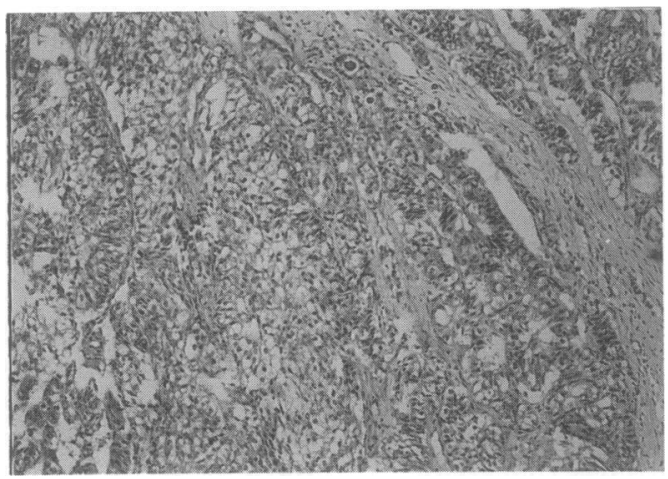

Figure 3 Pancreatic islets and tumour cells giving weak positive reaction for gastrin (immunoperoxidase $\times 100)$

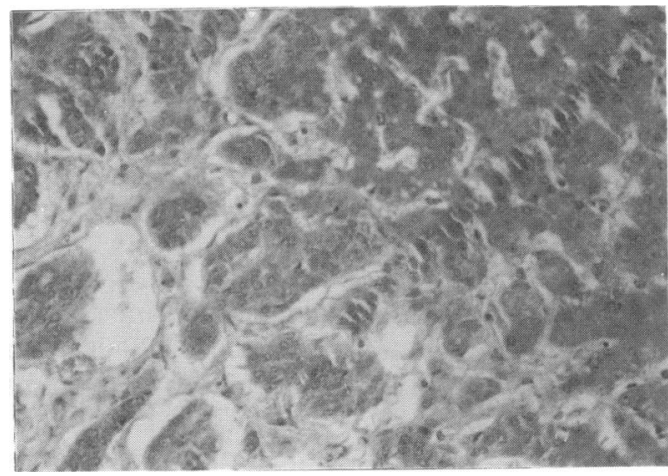

Figure 4 Metastatic tumour cells in the liver giving a weak positive reaction for gastrin (immunoperoxidase, $\times 200$ ) 
$3.4 \mathrm{mmol} / \mathrm{l}$, chloride $99 \mathrm{mmol} / \mathrm{l}$, total proteins $68 \mathrm{~g} / 1$, albumin $35 \mathrm{~g} / 1$, calcium $2.45 \mathrm{mmol} / 1$ and phosphorus $0.65 \mathrm{mmol} / \mathrm{l}$. Liver and kidney function tests were normal. The 24-hour urine 5-hydroxyindoleacetic acid (5-HIAA) level was $272 \mu \mathrm{mol}$, which was elevated. A chest $\mathrm{X}$-ray and an electrocardiogram were normal. An abdominal ultrasonogram showed biliary sludge and multiple metastatic nodules in the liver. Computed tomography of the abdomen confirmed multiple metastases in the liver. An echocardiogram showed a normal appearance of the heart. After admittance, she showed episodic attacks of hypotension along with flushing and diarrhoea. To control the signs of carcinoid syndrome, subcutaneous octreotide treatment, $100 \mu \mathrm{g}$ tid was initiated. During this therapy, the hypotensive attacks decreased, but did not disappear. The 24-hour urine 5-HIAA level regressed to $39 \mu \mathrm{mol}$, which was within normal range. Octreotide treatment was continued until the 32nd day of hospitalisation, on which a persistent severe hypotension resistant to dopamine infusion appeared. The patient died 24 hours later due to untreatable shock. Her family refused our request for an autopsy.

\section{Discussion}

In 1977, two cases of pancreatic somatostatinoma were reported, ${ }^{6,7}$ on the basis of which, and the known pharmacologic effects of somatostatin, a tentative description of the somatostatinoma syndrome was proposed. ${ }^{8}$ Knowledge of the pharmacologic actions of somatostatin allowed prediction of the clinical syndrome of excess somatostatin (see box 2). Of the 20 patients with a pancreatic somatostatinoma reported up to 1994 , the head of the pancreas was the location of the primary tumour in nine, the tail in five, one each in the ampullary region and the body and was unspecified or unknown in four cases. In most cases the presence of a somatostatinoma was documented by a combination of an increased plasma somatostatin level, immunocytochemical or hormonal content analysis demonstrating somatostatin as the major tumour secretory product, a clinical syndrome, and basal and stimulated endocrinologic studies compatible with somatostatin excess. In the majority of these patients, metastatic spread was evident at the time of presentation or shortly thereafter. ${ }^{1}$ It has been suggested that the expression of the classic triad of symptoms may be more common when liver metastases are present. ${ }^{3}$ As is common with other types of pancreatic endocrine tumour, many of these tumours secreted several different hormones such as adrenocorticotropic hormone, calcitonin, gastrin, insulin and glucagon; as well as vasoactive intestinal polypeptide, pancreatic polypeptide, prostaglandin $E_{2}$, gastrin-like substance and $\alpha$ endorphin..$^{1,3,5}$ In many cases, the clinical picture was dominated by the effect of the other hormones.

The classic triad of diabetes, gall bladder disease and steatorrhoea that comprises the somatostatinoma syndrome is frequently seen in the patient with a pancreatic somato-
Somatostatinoma: clinical features

- gallstones

- mild diabetes mellitus

- steatorrhoea

- diarrhoea

- dyspepsia

Box 2

\section{Learning points}

- a patient with pancreatic islet cell carcinoma should be evaluated carefully for the existence of a somatostatinoma

- as is common with other types of pancreatic endocrine tumour, a somatostatinoma may produce several different hormones such as adrenocorticotropic hormone, calcitonin, gastrin, insulin, and glucagon, as well as vasoactive intestinal polypeptide, pancreatic polypeptide, prostaglandin $\mathrm{E}_{2}$, gastrin-like substance and $\alpha$-endorphin

- a somatostatinoma may also cause carcinoid syndrome

- this situation may require exogenous administration of somatostatin or its analogue to control the signs of carcinoid syndrome

- the prognosis of pancreatic somatostatinoma with metastases is poor

\section{Box 3}

statinoma. However, as previously mentioned, the presence of concomitantly secreted hormones can drastically alter the clinical presentation. Several investigators have stressed the fact that the presence of the triad should not be considered necessary (or sufficient) for the diagnosis of somatostatinoma. The diabetes usually takes the form of a mild endogenous hyperglycaemia with significant postprandial rises in serum glucose level. The gall bladder disease takes the form of a dilated gall bladder with or without stones. Steatorrhoea is presumed to be due to pancreatic insufficiency induced by hypersomatostatinaemia. Pancreatic function has been shown to improve after resection of a pancreatic somatostatinoma in at least one patient. ${ }^{1}$ Survival of a patient with somatostatinoma depends on the coexistence of distant metastases as well as whether or not the primary tumour is resectable.

In the patient presented here, the main complaint was severe upper gastrointestinal bleeding which might have been a consequence of hypergastrinaemia (or Zollinger-Ellison syndrome) on first admission. Though the serum gastrin level was not detected preoperatively, it was found to be normal during the postoperative period. This finding supported the existence of a gastrin-secreting endocrine tumour which had metastasised to the liver, as the entire G-cell population had been removed by total gastrectomy. To our knowledge, this is the fourth case of pancreatic somatostatinoma secreting gastrin or gastrinlike substance, to appear in the literature. ${ }^{1,5,9}$

Our patient was re-admitted to the hospital nine months after surgery, with signs of car- 
cinoid syndrome. Diagnosis was confirmed by the high level of 5-HIAA in 24 hour urine. Although the carcinoid syndrome is known to occur in patients with pancreatic islet cell carcinoma, there has not to our knowledge been a report in the literature indicating its occurrence in a patient with somatostatinoma.

Somatostatin is known to inhibit hormone secretion from many endocrine tumours. As a peptide, it requires intravenous admission, but octreotide, a long-acting somatostatin analogue can be given subcutaneously. When given to patients with carcinoid syndrome, flushing and diarrhoea were promptly relieved in $88 \%$ while $72 \%$ had a decrease of $50 \%$ or more in urinary 5-HIAA levels. ${ }^{10}$ It is interesting to notice that, although there was a somatostatin-secreting

1 Estes BL, Krejs GJ. The inhibitory syndrome: somatostatinoma. In: Friesen SR, Thompson NW, eds. Surgical statinoma. In: Friesen SR, Thompson NW, eds. Surgical
endocrinology: clinical syndromes, 2nd edn. Philadelphia: JB endocrinology: clinical syndromes, 2nd edn
Lippincott Company, 1990; pp 249-66.

2 Krejs GJ, Collins SM, McCarthy D, Unger RH, Gardner JD. Follow-up of a patient with somatostatinoma. N Engl f Med 1986; 315: 1295

3 Pipeleers D, Couturier E, Gepts W, et al. Five cases of somatostatinoma: clinical heterogeneity and diagnostic usefulness of basal and tolbutamide-induced hypersomatostatinemia. F Clin Endocrinol Metab 1983; 56: 1236-42.

4 Kaplan EL, Udekwu A. The carcinoid syndromes. In Friesen SR, Thompson NW, eds. Surgical endocrinology: clinical syndromes, 2nd edn. Philadelphia: JB Lippincot Company, 1990; pp 181-209.

5 Gerlock AJ, Muhletaler CA, Halter S, Goncharenko V. Pancreatic somatostatinoma: histologic, clinical and angiographic features. AfR 1979; 133: 939-43. tumour and probably excess somatostatin in serum (which was demonstrated immunocytochemically but not biochemically), our patient required exogenous administration of a somatostatin analogue. This is difficult to explain but it may be that the somatostatin produced by the tumour itself is defective or inadequate to overcome excess serotonin production by the tumour cells.

In conclusion, one must keep in mind that somatostatinoma, as well as other endocrine pancreatic tumours, may cause carcinoid syndrome, and this situation may require exogenous administration of somatostatin or its analogue to control the signs of carcinoid syndrome.

6 Larsson LI, Hirsch MA, Holst JJ, et al. Pancreatic somatostatinoma: clinical features and physiological implications. Lancet 1977; 1: 666-8.

7 Ganda OP, Weir GC, Soeldner JS, et al. Somatostatinoma: a somatostatin-containing tumor of the endocrine pancreas. $N$ Engl f Med 1977; 296: 963-7.

Engl f Med 1977; 296: 963-7. Unger RH.

9 Asa SL, Kovacs K, Killinger DW, et al. Pancreatic islet-cell carcinoma producing gastrin, ACTH, $\alpha$-endorphin, somatostatin and calcitonin. Am $\mathcal{f}$ Gastroenterol 1980; 74: 30-4.

10 Kvols LK, Moertel CG, O'Connell MJ, Schutt AJ, Rubin J, Hahn RG. Treatment of the malignant carcinoid syndrome: evaluation of a long-acting somatostatin analogue. $N \mathrm{Englf}$ Med 1986; 315: 663-6. 